\title{
Assessment of PSA-Age volume score in predicting positive prostate biopsy findings in Turkey
}

\author{
Oktay Uçer ${ }^{1}$, Uğur Yücetaş ${ }^{2}$, İlker Çelen ${ }^{3}$, Gökhan Toktaş ${ }^{2}$, Talha Müezzinoğlu ${ }^{1}$ \\ ${ }^{1}$ Department of Urology, Faculty of Medicine, Celal Bayar University, Manisa, Turkey; ${ }^{2}$ Department of \\ Urology, Istanbul Teaching and Research Hospital, Istanbul, Turkey; ${ }^{3}$ Urology Clinic, Acipayam State \\ Hospital, Denizli, Turkey
}

\section{ABSTRACT}

Objectives: To evaluate PSA-age volume (AV) scores in predicting positive prostate biopsy findings in Turkey.

Materials and Methods: PSA-AV was calculated by multiplying the patient's age by the prostate volume and dividing it by the PSA level. Sensitivities and specificities of the PSA-AV were assessed by retrospective analysis of findings from 4,717 prostate biopsies.

Results: The population's average age was $63.71 \pm 7.63$ years, the mean PSA level was $9.73 \pm 17.01 \mathrm{ng} / \mathrm{mL}$, the mean prostate volume was $44.46 \pm 23.88 \mathrm{~cm}^{3}$. Of the 4,717 prostate biopsies, 1,171 biopsy specimens (24.8\%) were positive for prostate cancer. A PSA-AV score of 700 had a sensitivity and specificity of 95\% and 15\%, respectively. These values were similar to the sensitivity and specificity for a PSA cut-off of $4 \mathrm{ng} / \mathrm{mL}(94 \%$ and 13\%, respectively). Although the sensitivity of a PSA-AV cut-off of 700 in patients over 60 years was similar to the PSA cut-off of $4 \mathrm{ng} / \mathrm{mL}$ and the age-adjusted PSA, in patients $<60$ years, its sensitivity was higher. While the sensitivities of a PSA-AV cut-off of 700 in patients with low prostate volume was higher than a PSA cut-off of 4ng/ $\mathrm{mL}$, the sensitivities of both methods with moderate prostate volumes were similar.

Conclusions: Considering all the biopsies, the sensitivity and specificity of a PSA-AV of 700 for predicting positive biopsy findings were similar to a PSA of $4 \mathrm{ng} / \mathrm{mL}$. We suggest the PSA-AV cut-off of 700 should only be used in patients younger than 60 with low prostate volumes $\left(<20 \mathrm{~cm}^{3}\right)$.

\section{ARTICLE INFO}

Key words:

Prostate-Specific Antigen;

Prostatic Neoplasms; Prostate;

Biopsy; Digital Rectal Examination

Int Braz J Urol. 2015; 41: 864-8

Submitted for publication:

September 16, 2014

Accepted after revision:

March 24, 2015

\section{INTRODUCTION}

Regular serum prostate-specific antigen (PSA) evaluations and digital rectal examinations (DRE) are recommended for detecting PCa (1). However, the serum PSA level is the most widely used marker to detect this cancer in the general population. Because PSA is organ specific, but not disease specific, its use for prostate cancer screening lacks adequate sensitivity (2). Thus, due to the false- -positive results obtained by the PSA test during screening, many patients are subjected to an unnecessary transrectal ultrasound-guided prostatic biopsy (TRUSPB), which is an invasive procedure that can lead to significant morbidity, and even mortality $(3,4)$.

Recently, various strategies were introduced to improve the sensitivity and specificity of the PSA (5). In these studies, prostate volume, PSA level and age were clinically significant predictors of positive 
biopsy findings $(5,6)$. Patel et al. (7) developed a novel formula that incorporates age, prostate volume, race and PSA level into a single score for prostate cancer detection. The PSA-age volume (PSA$-\mathrm{AV}$ ) score is calculated by multiplying the age and prostate volume and then dividing the total by the pre-biopsy PSA. Patel et al. noticed the formula is useful for predicting positive biopsy findings. According to their data, the PSA-AV score was more sensitive in younger patients and in patients with a small prostate volume. They also reported that the PSA-AV score was more specific in older patients and in patients with a large prostate volume. The purpose of the present retrospective study was to evaluate the novel score in predicting positive prostate biopsy findings in Turkey.

\section{MATERIALS AND METHODS}

This retrospective study was based on the data of 5,299 TRUSPB procedures performed between 2005 and 2013 at the Department of Urology of the University Hospital in Manisa and the Clinic of Urology of the Teaching and Research Hospital in Istanbul, Turkey. The indications for performing a TRUSPB were elevated or increasing PSA levels, abnormal DRE findings or a previous abnormal TRUSPB. The database consisted of four variables including age, pre-biopsy PSA level, prostate volume and digital rectal examination information.

TRUSPBs were performed using the LOGIQ machine at both the University Hospital and the Teaching and Research Hospital by the urologists. The prostate volume was calculated using ultrasonography during the TRUSPB. The number of biopsy cores (6-12 cores) was determined by the urologists according to their preference. In patients with an abnormal DRE or ultrasound findings, additional biopsy cores were taken.

A total of 5,063 biopsy records were reviewed. We eliminated those biopsy records that did not have complete data, number of biopsy cores with less than 10 , patients who were $<40$ years or $>79$ years old, and patients who had undergone repeat biopsies. A total of 4,717 biopsy specimens were analysed. The PSA-age volume (PSA-AV) score was calculated by multiplying the age and prostate volume and then dividing the total by the pre-biopsy PSA level (7).
Patel et al. (7) stratified the PSA-AV score in intervals of 400, and also analysed the score to determine an effective cut-off score for predicting prostate cancer. The sensitivities and specificities of the PSA AV of 500 and 700 were also analysed since the PSA-AV of 500 or 700 were recommended as a PSA-AV cut-off in their study. Therefore we used PSA-AV of 500 and 700 as cut-off of PSA-AV. The sensitivities and specificities of PSA-AV of 500 and 700 were calculated in the patient groups divided according to age and prostate volume. The sensitivities and specificities of the age-adjusted PSA levels and PSA cut-off of $4 \mathrm{ng} / \mathrm{mL}$ were calculated. For the age-adjusted PSA data, patients were categorized into four categories, each with its own abnormal PSA value. The abnormal values were $>2.5 \mathrm{ng} / \mathrm{mL}$ (age 40-49 years), $>3.5 \mathrm{ng} / \mathrm{mL}$ (age $50-59$ years), $>4.5 \mathrm{ng} / \mathrm{mL}$ (age $60-69$ years), and $>6.5 \mathrm{ng} / \mathrm{mL}$ (age 70-79 years). Statistical analyses were carried out using SPSS 13.0 (SPSS Inc.). The study protocol was approved by the ethics committee of our institution.

\section{RESULTS}

The mean age of the patients in our study was $63.71 \pm 7.63(n=4,717)$. The mean PSA level and mean prostate volume were $9.73 \pm 17.01 \mathrm{ng} / \mathrm{mL}$ and $44.46 \pm 23.88 \mathrm{~cm}^{3}$, respectively (10\% trimmed mean). Of the 4,717 prostate biopsies, 1,171 biopsy specimens $(24.8 \%)$ were positive for prostate cancer.

The sensitivities and specificities of the PSA-AV scores in intervals of 400, PSA-AV of 500 and 700 , and PSA cut-off of $4 \mathrm{ng} / \mathrm{mL}$ are shown in Figure-1. The positive predictive value of the PSA-AV cut-off of 500 and 700 was 30\% and 27\%, respectively. The positive predictive value of the PSA cut-off of $4 \mathrm{ng} / \mathrm{mL}$ and the age-adjusted PSA method was 26\% and 25\%, respectively. Although using a PSA-AV cut-off of 700 decreased the number of biopsies by 114 , it led to 10 more detected cancer cases compared to using the PSA cut-off of $4 \mathrm{ng} / \mathrm{mL}$. In the same population, using a PSA cut-off of $4 \mathrm{ng} / \mathrm{mL}$ increased the biopsies taken by 875 compared with a PSA-AV cut-off of 500 and led to 95 more detected cancer cases. The sensitivity, specificity, positive predictive and negative predictive value changes within the age and prostate volume groups are listed in Tables 1 and 2. 


\section{DISCUSSION}

Significant research efforts are ongoing to identify the optimal PSA threshold to recommend a prostate biopsy in an asymptomatic patient (5, 8). Catalona et al. reported this PSA level or higher was appropriate as the PSA cut-off value for the screening of PCa. Since then, this value has been the most commonly used clinically. While its sensitivity is $67.5 \%$ to $80 \%$, the specificity is only $20 \%$ to $30 \%$ (9). Although PSA is a highly organ-specific marker, it is not a cancer-specific marker. Therefore, it may also show increases with age or other benign conditions, including benign prostate hyperplasia or prostate inflammation (10). Prostate- -specific antigen density (PSAD) was investigated to decrease the impact of prostate volume on the PSA level before deciding on a TRUSPB. Because studies using PSAD for prostate cancer screening have led to conflicting results, it is not widely used by clinicians (11). PSA-AV was developed by Patel et al. to correct the impact of prostate volume on PSA levels (7). They noticed that a PSA-AV score of 700 was a useful formula for predicting positive biopsy findings in patients with small prostates. According to their data, in patients with low to moderate prostate volumes $\left(<20 \mathrm{~cm}^{3}\right.$ and $\left.20-60 \mathrm{~cm}^{3}\right)$, a PSA-AV cut-off of 700 had sensitivities of 97\% and 91\%, respectively compared with sensitivities of $74 \%$ and $86 \%$ for a PSA cut-off of $4 \mathrm{ng} / \mathrm{mL}$. This

Table 1 - Sensitivity and specificity of various cut-off methods in different age groups.

\begin{tabular}{|c|c|c|c|c|c|c|}
\hline Variable & Total biopsies (n) & Cancers detected (n) & Sensitivity (\%) & Specificity (\%) & PPV (\%) & NPV (\%) \\
\hline \multicolumn{7}{|l|}{ Age $40-49$ years } \\
\hline Psa cut off $2.5 \mathrm{ng} / \mathrm{mL}$ & 120 & 12 & 85.7 & 6.1 & 10.0 & 77.8 \\
\hline Psa cut off $4.0 \mathrm{ng} / \mathrm{mL}$ & 91 & 9 & 64.3 & 28.7 & 9.9 & 86.8 \\
\hline Psaav cut off 700 & 123 & 14 & 100 & 5.2 & 11.4 & 100 \\
\hline Psaav cut off 500 & 108 & 13 & 92.9 & 17.4 & 12.0 & 95.2 \\
\hline \multicolumn{7}{|l|}{$50-59$ years } \\
\hline Psa cut off $3.5 \mathrm{ng} / \mathrm{mL}$ & 1191 & 199 & 91.7 & 12.0 & 16.7 & 88.2 \\
\hline Psa cut off $4.0 \mathrm{ng} / \mathrm{mL}$ & 1081 & 192 & 88.5 & 21.1 & 17.8 & 90.5 \\
\hline Psaav cut off 700 & 1224 & 213 & 98.2 & 10.3 & 17.4 & 96.7 \\
\hline Psaav cut off 500 & 1005 & 194 & 89.4 & 28 & 19.3 & 93.2 \\
\hline \multicolumn{7}{|l|}{$60-69$ years } \\
\hline Psa cut off $4.5 \mathrm{ng} / \mathrm{mL}$ & 1767 & 445 & 89.6 & 15.9 & 25.2 & 82.8 \\
\hline Psa cut off $4.0 \mathrm{ng} / \mathrm{mL}$ & 1908 & 472 & 95.0 & 8.7 & 24.7 & 84.5 \\
\hline Psaav cut off 700 & 1764 & 474 & 95.5 & 17.9 & 26.9 & 92.5 \\
\hline Psaav cut off 500 & 1408 & 424 & 85.3 & 37.4 & 30.1 & 89.0 \\
\hline \multicolumn{7}{|l|}{$70-79$ years } \\
\hline Psa cut off $6.5 \mathrm{ng} / \mathrm{mL}$ & 912 & 375 & 84.7 & 26.6 & 44.1 & 74.1 \\
\hline Psa cut off $4.0 \mathrm{ng} / \mathrm{mL}$ & 1128 & 430 & 97.1 & 4.6 & 38.1 & 72.3 \\
\hline Psaav cut off 700 & 983 & 412 & 93.0 & 22.0 & 41.9 & 83.9 \\
\hline Psaav cut off 500 & 812 & 377 & 85.1 & 40.6 & 46.4 & 81.8 \\
\hline
\end{tabular}

$\mathbf{P P V}=$ Positive predictive value; $\mathbf{N P V}=$ Negative predictive value; $\mathbf{P S A}=$ prostate-specific antigen; $\mathbf{P S A}-\mathbf{A V}=\mathbf{P S A}$-age volume . 
Table 2 - Sensitivity and specificity of PSA-AV cut-off of 700 and 500, and PSA cut-off of $4 \mathrm{ng} / \mathrm{mL}$ in different prostate volume groups.

\begin{tabular}{|c|c|c|c|c|c|c|}
\hline Variable & Total biopsies (n) & Cancers detected (n) & Sensitivity (\%) & Specificity (\%) & PPV (\%) & NPV $(\%)$ \\
\hline \multicolumn{7}{|l|}{ Prostate volume $<20 \mathrm{~cm}^{3}$} \\
\hline Psa cut off $4.0 \mathrm{ng} / \mathrm{mL}$ & 298 & 139 & 90.8 & 25.4 & 46.6 & 79.4 \\
\hline Psaav cut off 700 & 345 & 151 & 98.7 & 8.9 & 43.8 & 90.5 \\
\hline Psaav cut off 500 & 341 & 151 & 98.7 & 6.3 & 44.3 & 92.0 \\
\hline \multicolumn{7}{|l|}{ Prostate volume $20-60 \mathrm{~cm}^{3}$} \\
\hline Psa cut off $4.0 \mathrm{ng} / \mathrm{mL}$ & 2914 & 821 & 94.0 & 14.2 & 28.2 & 86.9 \\
\hline Psaav cut off 700 & 3072 & 849 & 97.3 & 8.8 & 27.6 & 90.0 \\
\hline Psaav cut off 500 & 2555 & 778 & 89.1 & 27.1 & 30.5 & 87.4 \\
\hline \multicolumn{7}{|l|}{ Prostate volume $60-100 \mathrm{~cm}^{3}$} \\
\hline Psa cut off $4.0 \mathrm{ng} / \mathrm{mL}$ & 786 & 116 & 100.0 & 5.4 & 14.8 & 100.0 \\
\hline Psaav cut off 700 & 553 & 91 & 78.4 & 34.7 & 16.5 & 90.8 \\
\hline Psaav cut off 500 & 358 & 63 & 54.3 & 58.3 & 17.6 & 88.6 \\
\hline
\end{tabular}

PPV = Positive predictive value; $\mathbf{N P V}=$ Negative predictive value; $\mathbf{P S A}=$ prostate-specific antigen; $\mathbf{P S A}-\mathbf{A V}=\mathbf{P S A}$-age volume.

makes it useful for ruling out prostate cancer. In patients with low to moderate prostate volumes $\left(<20 \mathrm{~cm}^{3}\right.$ and $\left.20-60 \mathrm{~cm}^{3}\right)$ in our study, a PSA-AV cut-off of 700 had sensitivities of 98\% and 97\%, respectively. The sensitivities of the PSA cut-off of $4 \mathrm{ng} / \mathrm{mL}$ were $91 \%$ and $94 \%$, respectively, in the same patient group. In both studies, the sensitivities of the PSA-AV cut-off of 700 were higher than the sensitivities of the PSA cut-off of $4 \mathrm{ng} / \mathrm{mL}$. However, the sensitivities of the PSA cut-off of $4 \mathrm{ng} / \mathrm{mL}$ in our study were higher compared with their study. Although their study had 687 patients (prostate volume $<60 \mathrm{~cm}^{3}$ ) receiving a TRUSPB, our study had 3,417 patients. Therefore, we think that our data is statistically more reliable. Our findings suggest that, although the sensitivities of PSA-AV cut-off of 700 in patients with low prostate volumes $\left(<20 \mathrm{~cm}^{3}\right)$ are higher than with a PSA cut-off of $4 \mathrm{ng} / \mathrm{mL}$, the sensitivities of the two methods in patients with moderate prostate volumes $\left(20-60 \mathrm{~cm}^{3}\right)$ are similar.

Considering all of the biopsies, we found that the sensitivities of a PSA-AV cut-off of 700 and a PSA cut-off of $4 \mathrm{ng} / \mathrm{mL}$ were 95\% and 94\%, respectively. Positive predictive values of a PSA-AV cut-off of 700 and a PSA cut-off of $4 \mathrm{ng} / \mathrm{mL}$ were $27 \%$ and $26 \%$, respectively. According to our data, the effectiveness of the PSA-AV cut-off of 700 compared with a PSA cut-off of $4 \mathrm{ng} / \mathrm{mL}$ are similar for predicting positive biopsy findings, considering all age groups and prostate volumes. Compared with using the PSA cut-off of $4 \mathrm{ng} / \mathrm{mL}$, using the PSA-AV of 700 decreased the number of biopsies by 114; however, it detected 45 more cancer cases. Patel et al. (7) noticed that using a PSA-AV cut-off of 700, rather than a PSA cut-off of $4 \mathrm{ng} / \mathrm{mL}$, led to 16 fewer biopsies with seven additional cancers detected.

Our data showed that in the 60-69-year-old population, the sensitivities of an age-adjusted PSA, a PSA cut-off of $4 \mathrm{ng} / \mathrm{mL}$ and a PSA-AV cut-off of 700 were 90\%, 95\% and 95\%, respectively. In this age group, the diagnostic values of these three methods for predicting positive prostate biopsy findings are similar to each other. In patients younger than 60, the sensitivity of the PSA-AV cut-off of 700 was higher than the age-adjusted PSA and the PSA cut-off of $4 \mathrm{ng} / \mathrm{mL}$ (Table-1). In the 50-59-year-old population, the sensitivities of the PSA cut-off of $4 \mathrm{ng} / \mathrm{mL}$, the PSA cut-off of $3.5 \mathrm{ng} /$ $\mathrm{mL}$ and a PSA-AV cut-off of 700 were $88 \%$, 91\% and $98 \%$, respectively. In this group, compared with using the PSA cut-off of $4 \mathrm{ng} / \mathrm{mL}$, using PSA-AV cut-off of 700 led to 143 more biopsies and 21 more 
cancer cases detected. Although the effectiveness of a PSA-AV cut-off of 700 in patients aged over 60 is similar to the other methods, in patients under 60 years old its effectiveness seems higher. Similarly, Patel et al. (7) suggest that a PSA-AV score of 700 is useful in ruling out cancer in younger patients.

US Preventive Services Task Force noticed that the amount of overdiagnosis of prostate cancer is an important concern because a man with cancer that would remain asymptomatic for the remainder of his life cannot benefit from screening or treatment (12). One of the limitations of our study was that we did not divide the patients into groups according to their Gleason score. Therefore we could not assess overdiagnosis of PCa and insignificant cancer in our study population. We suggest that further studies should evaluate the effect of PSA-AV formula on insignificant prostate cancer and overdiagnosis.

\section{CONCLUSIONS}

Our data supports the findings from the previous study that developed PSA-AV formula. However, in patients with a moderate prostate volume $\left(20-60 \mathrm{~cm}^{3}\right)$, we did not determine any superiority of the PSA-AV formula. Therefore, we suggest that the PSA-AV cut-off of 700 be used for predicting positive prostate biopsy findings in patients under the age of 60 and with low prostate volumes $\left(<20 \mathrm{~cm}^{3}\right)$. Further studies should evaluate the effectiveness of PSA and PSA-AV for predicting positive prostate biopsy findings in the patients without abnormal DRE.

\section{CONFLICT OF INTEREST}

None declared.
2. Catalona WJ, Smith DS, Ratliff TL, Dodds KM, Coplen DE, Yuan JJ, et al. Measurement of prostate-specific antigen in serum as a screening test for prostate cancer. N Engl J Med. 1991;324:1156-61. Erratum in: N Engl J Med 1991;325:1324.

3. Zaytoun OM, Anil T, Moussa AS, Jianbo L, Fareed K, Jones JS. Morbidity of prostate biopsy after simplified versus complex preparation protocols: assessment of risk factors. Urology. 2011;77:910-4.

4. Wagenlehner FM, van Oostrum E, Tenke P, Tandogdu Z, Çek M, Grabe M, et al. Infective complications after prostate biopsy: outcome of the Global Prevalence Study of Infections in Urology (GPIU) 2010 and 2011, a prospective multinational multicentre prostate biopsy study. Eur Urol. 2013;63:521-7.

5. Shahab AA, Soebadi DM, Djatisoesanto W, Hardjowijoto S, Soetojo S, Hakim L. Prostate-specific antigen and prostatespecific antigen density cutoff points among Indonesian population suspected for prostate cancer. Prostate Int. 2013;1:23-30.

6. Gregorio EP, Grando JP, Saqueti EE, Almeida SH, Moreira HA, Rodrigues MA. Comparison between PSA density, free PSA percentage and PSA density in the transition zone in the detection of prostate cancer in patients with serum PSA between 4 and $10 \mathrm{ng} / \mathrm{mL}$. Int Braz J Urol. 2007;33:151-60.

7. Patel S, Issa MM, El-Galley R. Evaluation of novel formula of PSA, age, prostate volume, and race in predicting positive prostate biopsy findings. Urology. 2013;81:602-6.

8. Oesterling JE, Jacobsen SJ, Chute CG, Guess HA, Girman CJ, Panser LA, et al. Serum prostate-specific antigen in a community-based population of healthy men. Establishment of age-specific reference ranges. JAMA. 1993;270:860-4.

9. Catalona WJ, Smith DS, Ratliff TL, Basler JW. Detection of organ-confined prostate cancer is increased through prostate-specific antigen-based screening. JAMA. 1993;270:948-54.

10. Beduschi MC, Oesterling JE. Prostate-specific antigen density. Urol Clin North Am. 1997;24:323-32.

11. Caplan A, Kratz A. Prostate-specific antigen and the early diagnosis of prostate cancer. Am J Clin Pathol. 2002;117:S104-8.

12. Moyer VA; U.S. Preventive Services Task Force. Screening for prostate cancer: U.S. Preventive Services Task Force recommendation statement. Ann Intern Med. 2012;157:120-34.

\section{REFERENCES}

1. Aslan $Y$, Tekdogan, Tuncel A, Uzun MB, Karabulut E, Atan A. Serum dehydroepiandrosterone sulfate usage for early detection of prostate cancer in men with serum prostate specific antigen level between 2.5 and $4.0 \mathrm{ng} / \mathrm{mL}$ : a pilot study. Turk J Med Sci. 2008;38:399-404.
Correspondence address: Oktay Ucer, MD Department of Urology, Faculty of Medicine, Celal Bayar University, Manisa, Turkey Telephone: + 90505 211-4618 E-mail: uceroktay@yahoo.com 